\title{
RANCANG BANGUN SISTEM INFORMASI MANAJEMEN SKRIPSI BERBASIS WEB MENGGUNAKAN MODEL WATERFALL
}

\author{
Ibnu Rusdi, Indra Febria Widy, Noviyanti Peratiwi \\ ${ }^{1}$ Teknik Informatika \\ Sekolah Tinggi Manajemen Informatika dan Komputer Nusa Mandiri \\ www.nusamandiri.ac.i \\ ibnu.ibr@nusamandiri.ac.id \\ 2,3 Teknik Informatika \\ Sekolah Tinggi Teknik Cendekia \\ Jl. Islamic Raya Kompleks Pendidikan Islamic Village Kelapa Dua Tangerang \\ www.cendekia.ac.id \\ 2 indra.febria@cendekia.ac.id, ${ }^{3}$ novi.per4tiwi@gmail.com
}

\begin{abstract}
Abstrak
Dalam tulisan ini akan dibahas mengenai proses pembuatan manajemen skripsi berbasis web. Penulis mengangkat tema ini karena saat ini mahasiswa sering sekali menjumpai permasalahan terhadap penulisan skripsi yang dimana membutuhkan banyak waktu dan juga membutuhkan banyak kertas untuk revisi dari dosen pembimbing. Konfirmasi penulisan sangatlah penting bagi para mahsiswa dalam proses pembuatan penulisan mahasiswa, yang ak- an dilakukan penilaian oleh para dosen pembimbing yang dimana kreatifitas mahasiswa terlihat dalam tahap-tahap proses pembuatan penulisan skripsi nanti. Model yang penulis gunakan menunjang Sistem Life Development Sistem (SDLC) yaitu Model Waterfall (Air Terjun) diharapkan dengan kemudahan dalam mengembangkan perangkat lunak (Software) pada setiap tahap yang dikerjakan saling mendukung satu sama lain. Tahapan pengerjaan dalam tulisan ini dimulai dari pengumpulan sumber permasalahan proses pembuatan penulisan mahasiswa dan menemukan tujuan untuk mempermudah mahasiswa dalam berkomunikasi dengan dosen pembimbing. Dengan adanya manajemen skripsi ini diharapkan bisa digunakan seba- gai data dalam membantu penulisan mahasiswa, dan membuat mahasiswa tidak harus menghamburkan kertas dalam revisi-revisi dari para dosen pembimbing.
\end{abstract}

Kata kunci: Sistem Informasi, Manajemen Skripsi, Model Waterfall

\begin{abstract}
In this paper we will discuss the process of making a web-based thesis management. The author raises this theme because currently students often encounter problems with thesis writing which requires a lot of time and also requires a lot of paper for revision from the supervisor. Writing confirmation is very important for students in the process of making student writing, which will be assessed by supervisors where student creativity is seen in the later stages of the thesis writing process. The model that the author uses supports the Sistem Life Development System (SDLC), namely the Waterfall Model (Waterfalls), which is expected to be easy in developing software (Software) at each stage that is done mutually supporting one another. Stages of work in this paper starts from gathering the source of the problem of the process of making student writing and finding a goal to facilitate students in communicating with the supervisor. With the management of this thesis it is hoped that it can be used as data in assisting students' writing, and making students not have to waste paper in the revisions of the supervisors.
\end{abstract}

Keywords: Information Sytems, Thesis Management, Waterfall Model

\section{PENDAHULUAN}

Dalam dunia Pendidikan perlu adanya pengendalian informasi yang terkomputerisasi untuk mendukung penyampaian informasi yang lebih cepat, tepat, dan terpusat sehingga mengharuskan kebutuhan ini untuk direalisasikan dalam segala bidang. Teknologi Informasi dan komunikasi sebagai bagian dari ilmu pengetahuan dan teknologi secara umum adalah semua 
teknologi yang berhubungan dengan pengambilan,pengumpulan,pengolahan,penyimpa nan,penyebaran, dan penyajian informasi (Abyzar, 2019). Pada penelitian sebelumnya dengan adanya sistem monitoring ini pihak akademik STIKOM Bali akan dengan mudah mengetahui perkembangan skripsi mahasiswa, sehingga jika terjadi kendala yang dihadapi oleh mahasiswa dalam pengerjaan skripsi maka pihak akademik dengan mudah dapat mencarikan solusinya(Ramayasa \& Arwana, 2015). Penulis mencoba merancang sebuah sistem agar mempermudah dosen dalam melakukan pemeriksaan skripsi mahasiswa dan memudahkan dosen untuk selalu berinteraksi ke mahasisawa tanpa harus mertemu langsung dengan siswa. Diharapkan sistem yang akan dikembangkan ini menjadi salah satu bentuk komputerisasi sistem konvensional untuk memberikan kemudahan dalam melakukan studi, dengan menggunakan teknologi secara optimal (Constantianus \& Suteja, 2005). Sistem yang dapat memudahkan mahasiswa untuk memanajement Skripsi dan memberikan approval kepada mahasiswa bimbingan, tanpa harus bertemu langsung dengan dosen. Penulis dalam merancang sistem menggunakan berbasis web agar dapat diakses secara mudah dan dibuat dengan user interface dinamis. Model pengembangan sistem yang digunakan dalam penelitian ini yaitu model Waterfall (Aediyansyah, 2018). Tujuan dikembangkan aplikasi manajemen skripsi agar dosen dan mahasiswa dapat berinteraksi secara interaktif sehingga kendala dosen yang sulit dihubungi dan sebagainya dapat berkurang dan memudahkan dalam proses pengontrolan dari bidang akademik.

\section{METODE PENELITIAN}

\section{Jenis Penelitian}

Penelitian ini menggunakan pendekatan kuantitatif dan terapan. Suatu proses menemukan pengetahuan yang menggunakan data berupa angka sebagai alat menganalisis keterangan mengenai apa yang ingin diketahui (Hidayat, 2012). Target/subjek penelitian (untuk penelitian kualitatif) atau populasi-sampel (untuk penelitian kuantitatif) perlu diurai dengan jelas dalam bagian ini(Friyadie \& Fatayat, 2019) .

\section{Model Pengembangan Sistem}

Model Waterfall atau air terjun menyediakan pendekatan alur hidup perangkat lunak secara sekuensial atau terurut dimulai dari analisis, desain, pengkodean, pengujian, dan tahap pendukung (support) (Sukamto \& Salahudin,
2018). Berikut tahapan-tahapan yang akan penulis kerjakan dengan metode pengembangan software Waterfall:

1. Analisis Kebutuhan Software

Pada tahap ini dilakukan eksplorasi mengenai kebutuhan dari pengguna (user). Yaitu dengan cara melakukan observasi pada STT Cedndikia mengenai masalah-masalah yang perlu diselesaikan seputar manajemen skripsi dan kebutuhan yang diperlukan bidang akademik. Diharapkan dengan pengembangan sistem ini diharapkan memudahkan proses monitoring, serta bagi dosen dengan mahasiswa proses bimbingan skripsi lebih interaktif.

2. Desain

Setelah kebutuhan dari pengembangan sistem informasi manajemn skripsi ini telah diketahui, maka akan dilakukan desain sistem. Desain sistem menggunakan UML (Activity Diagram, Usecase Diagram, Deployment Diagram) untuk desain database menggunakan Entity Relationship Diagram (ERD) dan Logical Record Structure (LRS).

3. Code Generation (Implementasi)

Pada tahap ini penulis menggunakan bahasa pemrograman PHP, HTML dan database phpMyAdmin sedangkan dalam proses pemrograman menggunakan Framework Codeigniter dengan fitur tampilan web dinamis dan User Friendly.

4. Testing

Pada tahap ini penulis mendeskripsikan proses pengujian yang akan dilakukan dengan menggunakan Blackbox testing untuk meminimalisir kesalahan (error) dan memastikan keluaran yang dihasilkan sesuai dengan yang diharapkan selain itu penulis menggunakan software uantuk menguji kemanan dari aplikasi web menggunakan Acunetix Threat.

5. Support

Dalam mendukung sistem informasi yang akan dikerjakan diperlukan perangkat keras (hardware) yaitu peralatan dalam bentuk fisik yang menjalankan perangkat lunak (software) dan peralatan ini berfungsi untuk menjalankan instruksi yang diberikan dan mengeluarkannya dalam bentuk informasi.

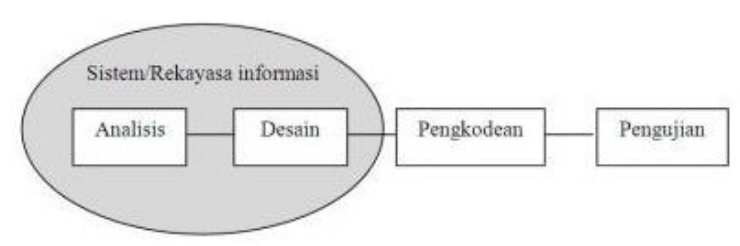

Gambar 1. Ilustrasi Model Waterfall 
Data, Intrumen, dan Teknik Pengumpulan Data

Untuk menunjang penelitian ini, penulis penulis menggunakan teknik pengumpulan data sebagai berikut:

1. Observasi

Metode ini dilakukan dengan pengamatan langsung terhadap sistem manajemen skripsi yang digunakan oleh Sekolah Tinggi Teknik (STT) Cendekia.

2. Wawancara

Metode ini merupakan suatu bentuk pengumpulan data dengan mengadakan tanya jawab langsung kepada Bidang Akademik Sekolah Tinggi Teknik (STT) Cendekia seputar objek yang akan diteliti. Wawancara ini digunakan untuk mengumpulkan informasi yang tidak mungkin diperoleh lewat observasi.

3. Studi Pustaka

Pada teknik ini, penulis mencari atau menggali informasi atau pengetahuan dari berbagai referensi yang bersumber dari buku, jurnal dan lainnya yang berkaitan dengan objek penelitian yang dibahas dalam penulisan.

\section{HASIL PENELITIAN DAN PEMBAHASAN}

\section{Analisa Kebutuhan Perangkat Lunak}

Langkah pertama yang dilakukan pada rancangan manajemen skripsi yang diterapkan, penulis mengidentifikasi kebutuhan yang diperoleh berdasarkan kebutuhan pengguna dan kebutuhan sistem. Halaman ini terbagi menjadi tiga tampilan. Tampilan pertama untuk administrator, yang kedua halaman untuk Dosen, dan yang ketiga halaman untuk Mahasiswa.

1. Halaman Untuk Bagian Admin

a. Mengelola data Mahasiswa.

b. Mengelola data Dosen .

2. Halaman Untuk Dosen

a. Dosen dapat melakukan login.

b. Pada halaman ini Dosen dapat mengelola data status penulisan yang disetujui

c. Dosen dapat mengelola data status pengajuan yang belum disetujui.

3. Halaman Untuk Mahasiswa

a. Pada halaman ini pengunjung dapat Mahasiswa melihat status penulisan.

b. Mahasiswa melakukan login.

c. Mahasiswa melakukan pengajuan perancangan penulisan.

\section{Perancangan Perangkat Lunak}

1. Perancangan Sistem Perangkat Lunak
Perancangan Sistem Informasi Manajemen Skripsi ini dengan menggunakan Use Case diagram. Use Case Diagram menggabarkan hubungan antara aktor dan kegiatan yang dapat dilakukannya terhadap aplikasi (Sukamto \& Salahudin, 2018).



Gambar 2. Use Case Diagram Rancang Bangun Skripsi

Tabel 1. Sekenario Use Case Login

\begin{tabular}{|c|c|c|}
\hline Use Case Name & : & $\begin{array}{l}\text { Login untuk } \\
\text { mengakses sistem }\end{array}$ \\
\hline $\begin{array}{l}\text { Use Case } \\
\text { Description }\end{array}$ & : & $\begin{array}{l}\text { Pengguna login ke } \\
\text { dalam sistem untuk } \\
\text { mengakses Fungsi- } \\
\text { fungsi sistem }\end{array}$ \\
\hline Actors & : & $\begin{array}{l}\text { Admin, Dosen, } \\
\text { mahasiswa }\end{array}$ \\
\hline Pre-Condition & : & $\begin{array}{l}\text { Pastikan jaringan } \\
\text { internet terkoneksi } \\
\text { agar tidak ada kendala } \\
\text { dalam mengakses } \\
\text { sistem }\end{array}$ \\
\hline Post- Condition & : & $\begin{array}{l}\text { Sistem akan } \\
\text { menampilkan popup } \\
\text { setelah berhasil login, } \\
\text { sesuai dengan hak } \\
\text { akses }\end{array}$ \\
\hline Main Scenarios & Serial & $\begin{array}{c}\text { Step } \\
\text { (Tahap/Langkah) }\end{array}$ \\
\hline \multirow[t]{3}{*}{ Actor } & 1 & $\begin{array}{l}\text { Input Username, } \\
\text { Input Password }\end{array}$ \\
\hline & 2 & $\begin{array}{l}\text { Validasi username } \\
\text { dan password }\end{array}$ \\
\hline & 3 & $\begin{array}{l}\text { Jika benar diberikan } \\
\text { akses ke sistem sesuai } \\
\text { hak akses }\end{array}$ \\
\hline Extension & $2 a$ & $\begin{array}{l}\text { Invalid username, } \\
\text { menampilkan popup } \\
\text { pesan username salah }\end{array}$ \\
\hline
\end{tabular}




\begin{tabular}{ll} 
2b $\quad \begin{array}{l}\text { Invalid Password, } \\
\text { menampilkan popup } \\
\text { pesan password salah }\end{array}$ \\
\hline
\end{tabular}

3. Perancangan Navigasi

a. Navigasi Halaman Pengguna Manajemen Skripsi.

2. Perancangan database

Perancangan basis data utama dengan menggunakan Entity Ralationship Diagram (ERD), dengan mengidentifikasi jenis entitas dan attribut.

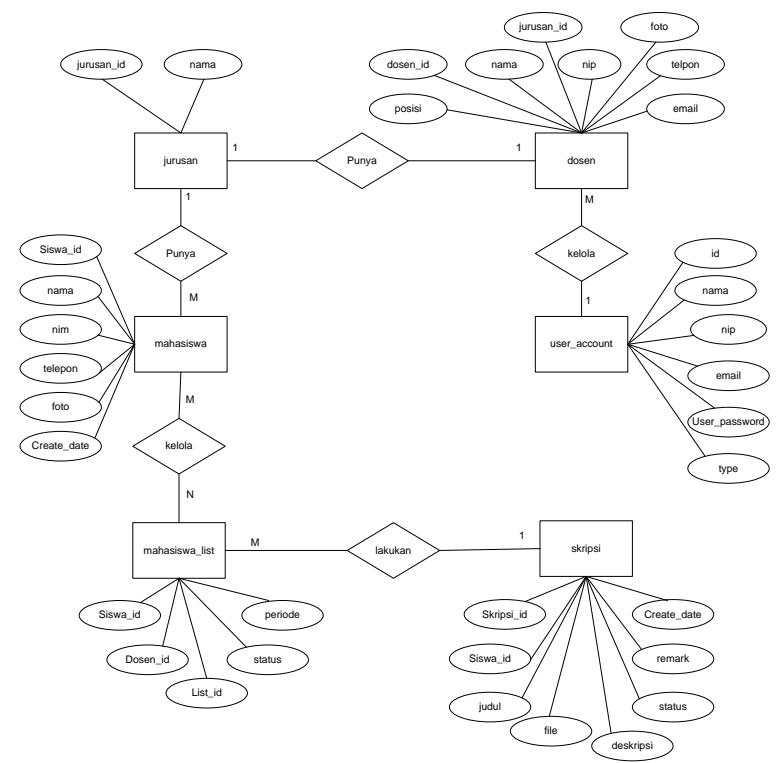

Gambar 3. Entity Relationship Diagram (ERD) Aplikasi Manajemen Skripsi

Perancangan Logical Record Structure (LRS), menjelaskan tentang alur dari suatu record.

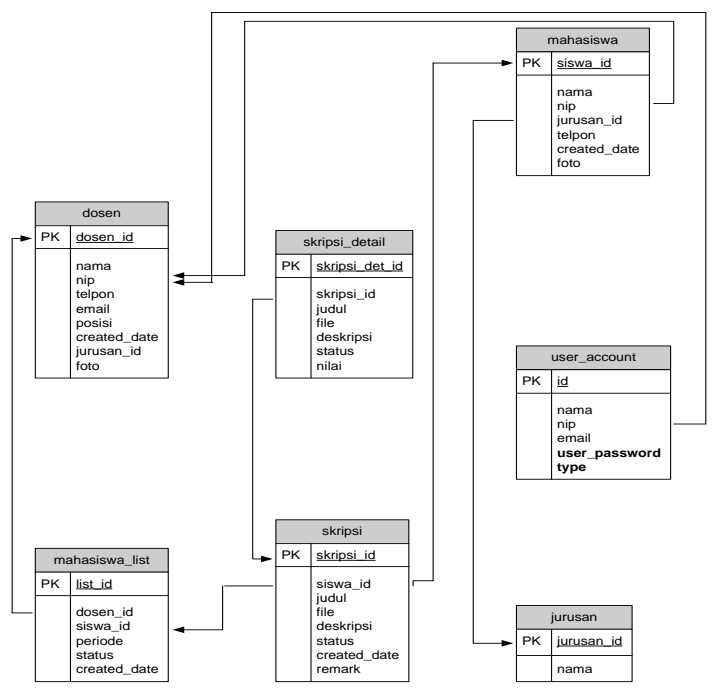

Gambar 4. Logical Record Structure Aplikasi Manajemen Skripsi



Gambar 5. Struktur Navigasi Aplikasi Manajemen Skripsi

4. Rancangan User Interface

a. Halaman Login Pengguna

Pada halam ini pengguna diinstruksikan memasukan atau input data dengan benar agar dapat mengakses sistem



Gambar 6. Tampilan Awal Login Pengguna

b. Tampilan Data Mahasiswa yang akan Skripsi

Data mahasiswa yang sudah memenuhi criteria untuk mengikuti Skripsi pada semester berjalan akan ditampilkan

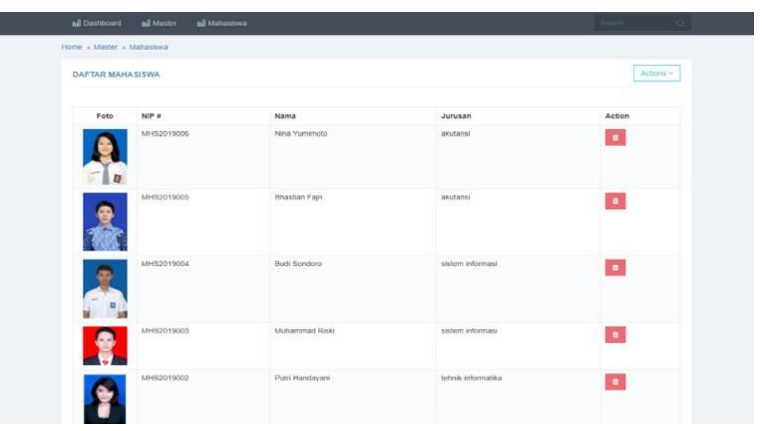

Gambar 7. Tampilan Data Mahasiswa yang skripsi 
c. Tampilan Data Dosen Pembimbing Skripsi Data dosen pembimbing yang telah memenuhi syarat membimbing mahasiswa untuk Skripsi pada STT Cendekia.

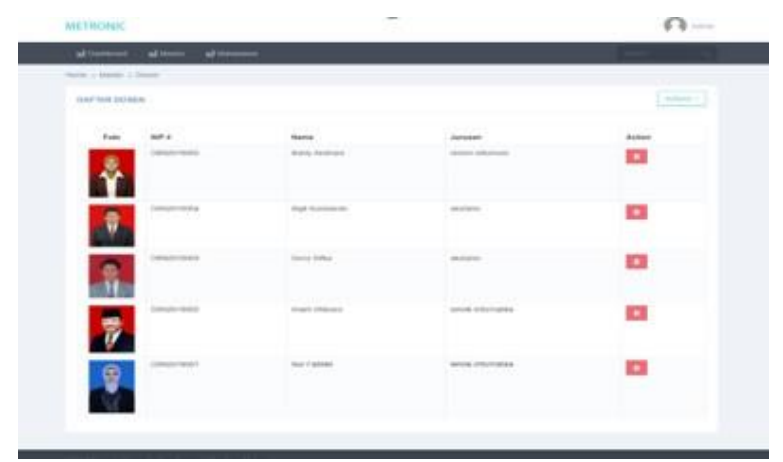

Gambr 8. Tampilan Data Dosen

Pada gambar 8 diatas, menampilkan daftar dosen STT Cendekia yang telah memenuhi syarat menjadi dosen pembimbing skripsi mahasiswa.

d. Tampilan Pengajuan Skripsi ke Dosen oleh mahasiswa



Pada gambar 9 diatas, menampilkan bentuk konsultasi mahasiswa kepada dosen pembimbing skripsi melalui aplikasi manajemen skripsi.

e. Tampilan Detail Skripsi Mahasiswa

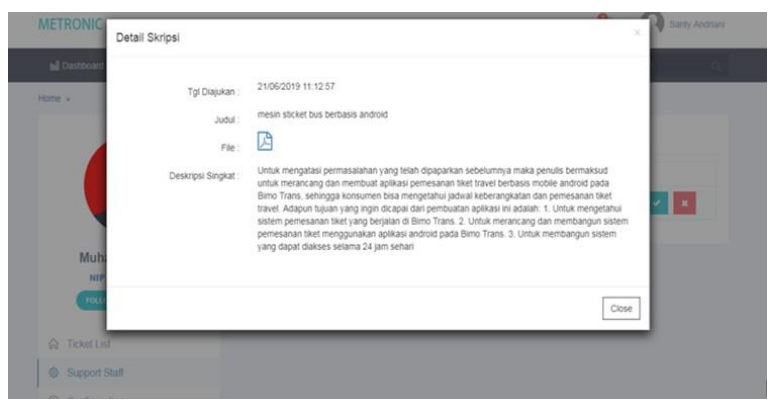

Gambar 10. Tampilan Detail Skripsi Mahasiswa
Pada gambar 10 diatas, mahasiswa STT Cendekia mengajukan per bab yang terdapat dalam skripsi. Sehingga dosen pembimbing dapat melihat dan mengecek file yang telah diajukan serta dosen diharapkan memberikan catatan terhadap pengajuan tersebut agar mahasiswa mengetahui yang harus diperbaiki atau revisi.

\section{f. Tampilan Persetujuan (Approve it) Skripsi Mahasiswa}

Pada tampilan berikut akan menampilkan data pesetujuan dosen kepada mahasiswa yang telah selesai mengerjakan skripsi dan berinteraksi aktif dalam Aplikasi Manajemen Skripsi.

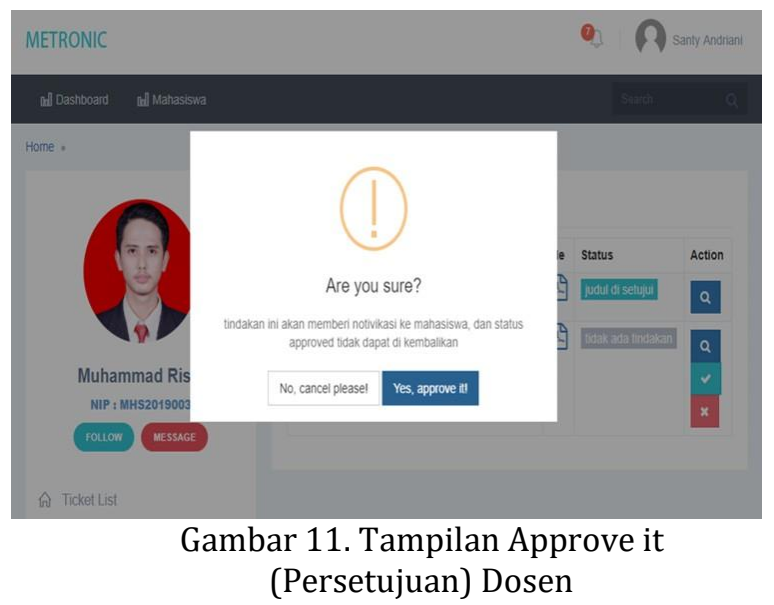

Pada gambar 11 diatas, apabila mahasiswa telah diperiksa semua pengajuan bab dan telah memperbaiki serta telah sesuai kaidah penulisan. Dosen pembimbing dapat memberikan persetujuan melalui aplikasi manajemen skripsi dan mahasiswa diwajibkan menemui serta meminta tanda tangan dosen pembimbing secara langsung.

\section{Code Perangkat Lunak}

$<$ div class="page-container" $>$ $<$ !-- BEGIN CONTENT -->

$<$ div class="page-content-wrapper">

$<$ !-- BEGIN CONTENT BODY -->

$<$ !-- BEGIN PAGE CONTENT BODY -->

$<$ div class="page-content" >

$<$ div class="container" $>$

$<$ !-- BEGIN PAGE BREADCRUMBS -->

$<$ ul class="page-breadcrumb breadcrumb">

$<\mathrm{li}>$

$<$ a href="index.html" $>$ Home $</$ a $>$

$<$ i class $=$ "fa fa-circle" $></$ i $>$

$</$ li $>$ 
$</$ ul $>$

$<$ !-- END PAGE BREADCRUMBS -->

$<$ !-- BEGIN PAGE CONTENT INNER -->

$<$ div class="page-content-inner">

$<$ div class $=$ "row" $>$

$<$ div class $="$ col-md-12">

$<$ !-- BEGIN PROFILE SIDEBAR -->

$<$ div class="profile-sidebar">

$<$ !-- PORTLET MAIN -->

$<$ div class="portlet light profile-sidebar-portlet ">

$<$ !-- SIDEBAR USERPIC -->

$<$ div class="profile-userpic" $>$

$<$ img

src $="<$ ?=base_url()? $>/$ uploads/mahasiswa $/<$ ?=

\$profile->foto?>" class="img-responsive" alt="">

$</$ div $>$

$<$ !-- END SIDEBAR USERPIC -->

$<$ !-- SIDEBAR USER TITLE -->

$<$ div class="profile-usertitle" $>$

$<$ div class="profile-usertitle-name" $>$

$<$ ?=ucwords(\$profile->nama)? $></$ div $>$

$<$ div class $=$ "profile-usertitle-job" $>$ NIP :

$<$ ?=ucwords(\$profile->nip)? $></$ div $>$

$</$ div $>$

$<$ !-- END SIDEBAR USER TITLE -->

$<$ !-- SIDEBAR BUTTONS -->

$<$ div class="profile-userbuttons">

$<$ button type="button" class="bth btn-circle green btn-sm" $>$ Follow $<$ /button $>$

$<$ button type="button" class="btn btn-circle red btn-sm" $>$ Message $<$ /button $>$

$</$ div $>$

$<!--$ END SIDEBAR BUTTONS -->

$<$ !-- SIDEBAR MENU -->

$<$ div class="profile-usermenu" $>$

$<$ ul class="nav" $>$

$<\mathrm{li}>$

$<$ a href="app_ticket.html">

$<$ i class="icon-home" $></$ i $>$ Ticket List $</$ a $>$

$</$ li $>$

$<$ li class $=$ "active" $>$

$<$ a href="app_ticket_staff.html">

$<$ i class $=$ "icon-settings" $></$ i $>$ Support Staff $</$ a $>$

$</ \mathrm{li}>$

$<$ li $>$

$<$ a href="app_ticket_config.html">

$<$ i class="icon-info" $></$ i $>$ Configurations $</$ a $>$

$</$ li $>$

$</$ ul $>$

$</$ div $>$

$<$ !-- END MENU -->

$</$ div $>$

$<$ !-- END PORTLET MAIN -->

$</$ div $>$

$<$ !-- END BEGIN PROFILE SIDEBAR -->

$<$ !-- BEGIN TICKET LIST CONTENT -->
$<$ div class="app-ticket app-ticket-list">

$<$ div class $="$ row" $>$

$<$ div class="col-md-12">

$<$ div class="portlet light ">

$<$ div class="portlet-title tabbable-line" >

$<$ div class="caption caption-md" $>$

$<$ i class="icon-globe theme-font hide" $></$ i $>$

$<$ span class="caption-subject font-blue-madison bold uppercase" $>$ List Judul Skripsi</span>

$</$ div $>$

$<$ div class="pull-right" $>$

$<$ div class="btn-group pull-right" >

$<$ button class="bth green btn-outline dropdowntoggle" data-toggle $=$ "dropdown" $>$ Actions

$<$ i class $=$ "fa fa-angle-down" $></$ i $>$

$<$ /button $>$

$<$ ul class="dropdown-menu pull-right" > $<$ li $>$

$<$ a dataction="add" title="add" dataid="" onclick="get_modal(this)">

$<$ script $>$

\section{Pengujian Perangkat Lunak}

Tabel 2. Pengujian Login Dosen

\begin{tabular}{|c|c|c|c|c|c|}
\hline No & $\begin{array}{c}\text { Skenario } \\
\text { pengujian }\end{array}$ & Test case & $\begin{array}{c}\text { Hasil yang } \\
\text { diharapkan }\end{array}$ & $\begin{array}{c}\text { Hasil } \\
\text { pengujia } \\
\mathbf{n}\end{array}$ & $\begin{array}{c}\text { Kesimpula } \\
\mathrm{n}\end{array}$ \\
\hline 1. & $\begin{array}{l}\text { Nama user } \\
\text { dan } \\
\text { Password } \\
\text { tidak diisi } \\
\text { kemudian } \\
\text { klik tombol } \\
\text { login }\end{array}$ & $\begin{array}{l}\begin{array}{l}\text { Nama user: } \\
\text { (kosong) }\end{array} \\
\text { Password: } \\
\text { (kosong) }\end{array}$ & $\begin{array}{l}\text { Sistem akan } \\
\text { menolak } \\
\text { akses dan } \\
\text { menampilka } \\
\text { n pesan } \\
\text { "Login Gagal" }\end{array}$ & $\begin{array}{c}\text { Sesuai } \\
\text { harapan }\end{array}$ & Valid \\
\hline 2. & $\begin{array}{l}\text { Mengetikka } \\
\text { n Nama user } \\
\text { dan } \\
\text { Password } \\
\text { tidak diisi } \\
\text { atau kosong } \\
\text { kemudian } \\
\text { klik tombol } \\
\text { login }\end{array}$ & $\begin{array}{l}\text { Nama user: } \\
16091500 \\
1 \\
\\
\text { Password: } \\
\text { (kosong) }\end{array}$ & $\begin{array}{l}\text { Sistem akan } \\
\text { menolak } \\
\text { akses dan } \\
\text { menampilka } \\
\text { n pesan } \\
\text { "Login Gagal" }\end{array}$ & $\begin{array}{c}\text { Sesuai } \\
\text { harapan }\end{array}$ & Valid \\
\hline 3. & $\begin{array}{l}\text { Nama user } \\
\text { tidak di isi } \\
\text { (kosong) } \\
\text { dan } \\
\text { Password } \\
\text { diisi } \\
\text { kemudian } \\
\text { klik tombol } \\
\text { login }\end{array}$ & $\begin{array}{l}\text { Nama user: } \\
\text { (kosong) } \\
\text { Password: } \\
\text { admin }\end{array}$ & $\begin{array}{l}\text { Sistem akan } \\
\text { menolak } \\
\text { Akses dan } \\
\text { menampilka } \\
\text { n pesan } \\
\text { "Login Gagal" }\end{array}$ & $\begin{array}{c}\text { Sesuai } \\
\text { harapan }\end{array}$ & Valid \\
\hline 4. & $\begin{array}{l}\text { Mengetikka } \\
\mathrm{n} \\
\text { salah satu } \\
\text { kondisi } \\
\text { salah pada } \\
\text { Nama user } \\
\text { atau } \\
\text { Password } \\
\text { kemudian } \\
\text { klik tombol } \\
\text { login }\end{array}$ & $\begin{array}{l}\text { Nama user: } \\
16091500 \\
1 \\
\text { (benar) } \\
\\
\text { Password: } \\
12345 \\
\text { (salah) }\end{array}$ & $\begin{array}{l}\text { Sistem akan } \\
\text { menolak } \\
\text { akses akan } \\
\text { kembali } \\
\text { diarahkan ke } \\
\text { halaman } \\
\text { login } \\
\text { dan } \\
\text { menampilka } \\
\text { n pesan “" } \\
\text { Login Gagal” }\end{array}$ & $\begin{array}{c}\text { Sesuai } \\
\text { harapan }\end{array}$ & Valid \\
\hline
\end{tabular}




\begin{tabular}{clllcc}
\hline No & $\begin{array}{c}\text { Skenario } \\
\text { pengujian }\end{array}$ & Test case & $\begin{array}{c}\text { Hasil yang } \\
\text { diharapkan }\end{array}$ & $\begin{array}{c}\text { Hasil } \\
\text { pengujia } \\
\text { n }\end{array}$ & $\begin{array}{c}\text { Kesimpula } \\
\text { n }\end{array}$ \\
\hline 5. & Mengetikka & Nama user & Sistem akan & Sesuai & Valid \\
& n Nama user & $:$ & menerima & harapan & \\
& dan & 16091500 & akses login & & \\
& Password & 1 & dan akan & & \\
dengan data & (benar) & menampilka & & \\
yang benar & & n pesan & & \\
kemudian & Password: & "Login & & \\
klik tombol & ****** & Berhasil!". & & \\
& login & (benar) & & & \\
& & & & & \\
\hline
\end{tabular}

Hasil pengujian keamanan menggunakan software Acunetix Web Vulnerability Scanner terhadap aplikasi Manajemen Skripsi yang sudah di hosting dengan laman http://skripsinovi.cendekia.vclass.my.id/ ditunjukan pada gambar berikut:

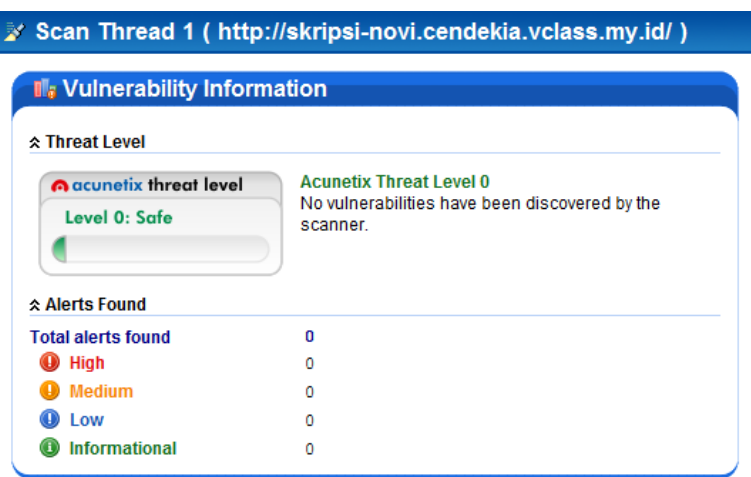

Gambar 12. Tampilan Threat Level Hasil Pengujian Keamana

Pada gambar diatas level 0: safe menunjukan aplikasi manajemen skripsi aman digunakan.

\begin{tabular}{|c|c|}
\hline \multicolumn{2}{|l|}{ i Target Information } \\
\hline $\begin{array}{l}\text { Target } \\
\text { Server banner } \\
\text { Operating system } \\
\text { Web server } \\
\text { Technologies } \\
\text { ᄎ Web Scan Progress }\end{array}$ & $\begin{array}{l}\text { http://skripsi-novi.cendekia.vclass.my.id/ } \\
\text { Apache } \\
\text { Unknown } \\
\text { Apache }\end{array}$ \\
\hline Start time & $21 / 11 / 2019,15: 47: 08$ \\
\hline Finish time & $21 / 11 / 2019,17: 27: 34$ \\
\hline Scan time & 1 hours, 40 minutes \\
\hline Scan iteration & \\
\hline Scanning mode & Heuristic \\
\hline Scanning stage & Finished \\
\hline Current module & Finished \\
\hline Testing on & Finished \\
\hline Current test(s) & Finished \\
\hline Running tasks & N/A \\
\hline Total number of requests & 18218 \\
\hline Average response time (ms) & 483,62 \\
\hline
\end{tabular}

Gambar 13. Tampilan Hasil Scan dengan aplikasi Acunetix Web Vulnerability Scanner

\section{SIMPULAN DAN SARAN}

\section{Simpulan}

Proses pengembangan aplikasi ini berhasil untuk membuat komunikasi mahasiswa bersama dosen menjadi lebih mudah, ramah linkungan,dapat memperlihatkan tahap proses pembuatan skripsi mahasiswa, dan memperlihatkan perkembangan maupun kreatifitas mahasiswa, juga dapat mempermudah mahasiswa untuk mengerjakan penulisan tanpa harus bertatapan langsung dengan dosen pembimbing. Memudahkan Bidang Akademik memonitoring kegiatan bimbingan serta pemetaan pembimbing skripsi menjadi lebih baik kedepan.

\section{Saran}

Dalam pembuatan aplikasi ini masih terdapat banyak yang perlu dibe- nahi agar aplikasi ini menjadi semakin baik dan efektif. Saran untuk penelitian di masa datang Perlunya keterangan waktu pembuatan penulisan untuk memperjelas waktu penulisan yang di buat mahasiswa, Tampilan menu type teks dibuat agar lebih menarik dan lebih bervariasi. dalam pengiriman file untuk diajukan ke dosen pembimbing terlebih dahulu diidentifikasi berupa file .doc atau docx bukan berupa .pdf agar dosen pembimbing dapat dengan mudah memberikan komentar dan memberikan saran perbaikan.

\section{DAFTAR REFERENSI}

Abyzar, A. (2019). Perkembangan Teknologi Informasi dan Komunikasi Bidang Pendidikan di Indonesia. Retrieved from www.kompasina.com website: https://www.kompasiana.com/abyzarchelse a0074/5d9c9d0c097f366b992563d2/perke mbangan-teknologi-informasi-dankomunikasi-pada-bidang-pendidikan-diindonesia

Aediyansyah, A. (2018). PERANCANGAN SISTEM INFORMASI PENJUALAN DAUR ULANG BOTOL BEKAS (PET) BERBASIS WEB. JURNAL RISET INFORMATIKA, 1(1), 11-16. Retrieved from http://ejournal.kresnamediapublisher.com/i ndex.php/jri/article/view/5

Constantianus, F., \& Suteja, B. R. (2005). Analisa dan Desain Sistem Bimbingan Tugas Akhir Berbasis Web dengan Studi Kasus Fakultas Teknologi Informasi. Jurnal Informatika UKM, 1(2), 93-105. Retrieved from https://media.neliti.com/media/publications /219183-analisa-dan-desain-sistembimbingan-tuga.pdf

Friyadie, F., \& Fatayat, U. (2019). PENGGUNAAN MODEL WATERFALL DALAM 
PERANCANGAN APLIKASI PENJUALAN KOSMETIK BERBASIS WEB. JURNAL RISET INFORMATIKA, 1(4), 159-166. Retrieved from

http://ejournal.kresnamediapublisher.com/i ndex.php/jri/article/view/84

Hidayat, A. (2012). Pengertian dan Penjelasan Penelitian Kuantitatif - Lengkap - Uji Statistik. Retrieved November 21, 2019, from Statistikian.Com website: https://www.statistikian.com/2012/10/pen elitian-kuantitatif.html

Ramayasa, I. P., \& Arwana, I. B. K. S. (2015). Perancangan Sistem Monitoring Pengerjaan Skripsi Pada Stmik Stikom Bali Berbasis Web. Konferensi Nasional Sistem Dan Informatika, 760-765. Retrieved from https://pdfs.semanticscholar.org/4752/7e6 1c8ceb57f209080665654efb53ac5486e.pdf

Sukamto, R. A., \& Salahudin, M. (2018). Rekayasa Perangkat Lunak Terstruktur Dan Berorientasi Objek (Edisi Revisi). Retrieved from https://scholar.google.co.id/scholar?hl=id\&a s_sdt $=0,5 \&$ cluster $=4129280622857038994$ 